\title{
Clinical impact of routine angiographic follow-up after percutaneous coronary interventions on unprotected left main
}

\author{
Cristina Aurigemma, Francesco Burzotta, Italo Porto, Giampaolo Niccoli, \\ Antonio Maria Leone, Filippo Crea, Carlo Trani \\ Institute of Cardiology, Catholic University of the Sacred Heart, Rome, Italy
}

\begin{abstract}
Background: Patients undergoing percutaneous coronary intervention (PCI) with drug-eluting stent (DES) on unprotected left main (ULM) represent a complex subset. The role of routine coronary angiography at follow up in this subset remains debated.

Methods: At the documented center, all patients undergoing successful PCI on ULM lesions performing angiographic follow-up is suggested, but adherence to such a recommendation is inhomogeneous. Consecutive patients undergoing DES PCI on ULM were enrolled and experienced no adverse events during the first 6 months. Patients were then allocated to two groups: those undergoing routine control angiography $(C A)$ and those undergoing clinical follow-up $(C F)$. Primary endpoint was major adverse cardiac events (MACE) defined as cardiac death, myocardial infarction and urgent repeat target vessel revascularization.
\end{abstract}

Results: A total of 190 patients underwent successful DES implantation on ULM and the study population was without early events. CA was performed at 6 months after the index procedure in 91 (48\%) patients. After $35 \pm 21$ months, MACE rates were significantly more common in the CF group as compared with the CA group (16.2\% vs. $4.3 \%, p=0.009)$. At multivariable analysis, CA was associated with reduced MACE risk (HR 0.13, 95\% CI 0.1-0.7, $p=0.028$ ). Of note, this was mainly driven by higher cardiac death rate in those undergoing $C F$ than in those undergoing $C A(p=0.01)$.

Conclusions: CA after complex PCI, such as ULM PCI, is associated with reduced MACE. Such an observation calls for appropriately designed randomized trials. (Cardiol J 2018; 25, 5: 582-588)

Key words: coronary angiography, percutaneous coronary interventions, unprotected left main

\section{Editorial p. 571}

\section{Introduction}

Percutaneous coronary intervention (PCI) for complex lesions, such as unprotected left main (ULM) disease has improved over time. After successful PCI, controlled randomized studies comparing follow-up strategies are lacking. Routine control angiography is commonly used in studies assessing restenosis rate $[1,2]$. Such an approach has been recognized to be associated with a detectable, albeit small, risk of morbidity and mortality [3-5]. Moreover, arguments in favor of repeat revascularization in the presence of asymptomatic restenosis are scarce [6] and the clinical impact of routine control angiography on long-term survival has been challenged [7-9]. On this basis, guidelinewriting authorities recommend a control angiography after PCI in restricted clinical situations such as patients complaining of angina symptoms or presenting signs of ischemia [10]. Nevertheless, since patients with angiographically-proven reste-

Address for correspondence: Francesco Burzotta, MD, PhD, Institute of Cardiology, Catholic University of the Sacred Heart, L.go Gemelli 8, 00168 Rome, Italy, tel: + 39 3494295290, fax: + 3906 3055535, e-mail: francesco.burzotta@unicatt.it 


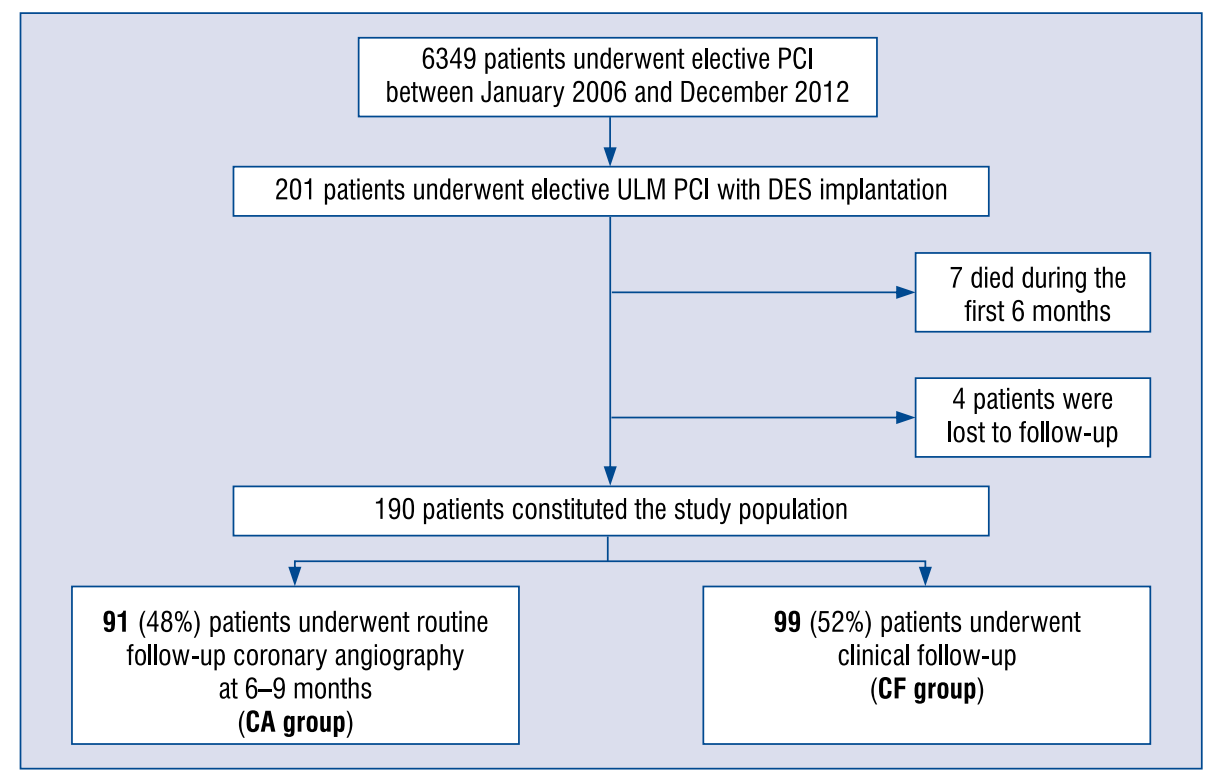

Figure 1. Study flow-chart; CA - coronary angiography; CF — clinical follow-up; DES - drug-eluting stent; $\mathrm{PCl}$ - percutaneous coronary intervention; ULM - unprotected left main.

nosis have worse prognosis at long-term follow-up [11-13], when dealing with patients at higher risk, planned coronary angiography may be considered.

In the present study, it was sought to assess the clinical impact of routine control angiography in patients undergoing successful PCI on complex lesions such as ULM diseases.

\section{Methods}

\section{Study design}

A retrospective observational study was conducted which included consecutive patients who underwent successful PCI with drug-eluting stent (DES) implantation for ULM lesions at the documented center between January 2006 and December 2012. During the study period, in accordance with internal protocol at the present institution, patients undergoing successful PCI on ULM lesions were recommended to undergo routine control angiography at 6-9 months. However, adherence to our recommendation was inhomogeneous due to referring physician and patient preference. As a consequence, some patients only received coronary angiography (CA) at follow up while the others underwent non-invasive clinical follow-up (CF).

Clinical and procedural characteristics were prospectively collected for each patient and entered into a dedicated catheterization laboratory database (Estensa, Esaote, Genoa, Italy).

The left main coronary artery was defined as unprotected in the absence of previous coronary artery bypass grafting (CABG) and if $\mathrm{CABG}$ had been performed but grafts to the left coronary system were occluded. PCI was defined successful if a stent was implanted, visual final diameter stenosis was $\leq 20 \%$ and a thrombolysis in myocardial infarction (TIMI) 3 flow in the treated segment. Pre and post-dilatation, kissing balloon dilatation, ventricular assistance and adjunctive intravascular imaging were used at the operator's discretion.

The study flow-chart is reported in Figure 1. Briefly, patients who had undergone successful PCI with DES implantation on ULM were first retrospectively identified. Then, patients with adverse events occurring during the first 6 months were excluded. The selected study population was allocated into two groups: patients who received $\mathrm{CA}$ and those who underwent $\mathrm{CF}$.

For all patients enrolled, clinical records were carefully evaluated and clinical follow-up was obtained by outpatient visit (in patients who decided to be followed-up at this Institution) or by telephone interview (for the remaining patients).

\section{Study end-points}

Primary composite endpoint was major adverse cardiac events (MACE), defined as cardiac death, myocardial infarction (MI) and urgent repeat target vessel revascularization (TVR) occurring after 6 months during follow-up.

Cardiac death was defined as any death without clear non-cardiac cause. MI during the follow-up was diagnosed according to clinical symptoms, 
Table 1. Baseline characteristics of the study groups.

\begin{tabular}{|c|c|c|c|c|}
\hline & $\begin{array}{c}\text { All } \\
(n=190)\end{array}$ & $\begin{array}{l}\text { CA group } \\
(\mathrm{n}=91)\end{array}$ & $\begin{array}{l}\text { CF group } \\
(\mathrm{n}=99)\end{array}$ & $\begin{array}{c}P \\
\text { (1 vs. 2) }\end{array}$ \\
\hline Age [years] & $69 \pm 10$ & $66 \pm 10$ & $71 \pm 10$ & 0.5 \\
\hline Male & $155(81 \%)$ & $75(82.4 \%)$ & $80(79.2 \%)$ & 0.3 \\
\hline \multicolumn{5}{|l|}{ Risk factors: } \\
\hline Diabetes & $55(28.9 \%)$ & $27(29.7 \%)$ & $28(27.7 \%)$ & 0.4 \\
\hline Hypertension & $154(81 \%)$ & $71(78.0 \%)$ & $83(82.2 \%)$ & 0.3 \\
\hline Dislipidemia & $117(61.5 \%)$ & $58(63.7 \%)$ & $59(58.4 \%)$ & 0.3 \\
\hline Current smokers & $36(18.9 \%)$ & $17(18.7 \%)$ & $19(18.8 \%)$ & 0.6 \\
\hline Renal failure: & $23(12.1 \%)$ & $8(8.8 \%)$ & $15(14.9 \%)$ & 0.2 \\
\hline History of Ml & $43(22.6 \%)$ & $15(16.5 \%)$ & $28(27.7 \%)$ & 0.05 \\
\hline Prior $\mathrm{PCl}$ & $54(28 \%)$ & $26(28.6 \%)$ & $28(27.7 \%)$ & 0.5 \\
\hline Prior CABG & $22(11.5 \%)$ & $9(8.8 \%)$ & $13(12.9 \%)$ & 0.3 \\
\hline Mild LVEF disfunction (EF 49-30) & $27(14.2 \%)$ & $11(12.1 \%)$ & $16(15.8 \%)$ & 0.3 \\
\hline Severe LVEF disfunction (EF < 30) & $17(8.9 \%)$ & $8(8.8 \%)$ & $9(8.9 \%)$ & 0.6 \\
\hline \multicolumn{5}{|l|}{ Admission diagnosis: } \\
\hline Stable angina & $136(71.7 \%)$ & $68(74.7 \%)$ & $68(68.7 \%)$ & 0.15 \\
\hline NSTEMI & $18(9.4 \%)$ & $7(7.7 \%)$ & $11(10.9 \%)$ & 0.3 \\
\hline Unstable angina & $36(18.9 \%)$ & $16(17.6 \%)$ & $20(20.4 \%)$ & 0.5 \\
\hline
\end{tabular}

CA — coronary angiography; CF — clinical follow-up; CABG — coronary artery bypass grafting; LVEF — left ventricular ejection fraction; $\mathrm{MI}$ - myocardial infarction; NSTEMI — non-ST-segment elevation myocardial infarction; PCl - percutaneous coronary intervention

electrocardiographic changes and elevation of cardiac biomarkers as explained in the third universal definition [14].

Urgent TVR was defined as TVR occurring in the setting of an unplanned hospitalization due to documented or suspected acute myocardial ischemia.

Secondary end-points included the individual components of primary end-point and the composite of cardiac death and MI. Another secondary end-point was any TVR including those performed at the time of planned CA.

\section{Statistical analyses}

Continuous variables were expressed as mean \pm standard deviation, categorical data as $\mathrm{n} / \mathrm{N}(\%)$. The $\chi^{2}$ or Fisher exact tests were used for categorical variables. $P$ value $<0.05$ was considered significant. Multivariable Cox proportional hazard model adjusted for potential confounding variables were used to assess the independent role of routine control angiography in the risk for MACE. The model included all clinical features reporting a difference between the two groups plus cardiovascular risk factors, age, sex, clinical presentation, number of diseased vessels, number of treated vessels, stent type and stent length. The rates of freedom from major events were constructed according to Kaplan and Meier, and comparisons were made using the log-rank test. The SPSS 18.0 statistical software (SPSS Italia, Inc., Firenze, Italia) was used for analyses.

\section{Results}

The study flow-chart is reported in Figure 1. Out of 6349 patients who underwent elective PCI at the present institution during the study period, 201 patients underwent elective ULM PCI and were eligible for the study. Eleven patients were then excluded: 7 died during the first 6 months and 4 patients were lost to follow-up. Thus, a total of 190 patients constituted the study population. Out of these, 91 (48\%) patients had elective followup coronary angiography and constituted the CA group while the remaining $99(52 \%)$ constituted the $\mathrm{CF}$ group.

Baseline clinical characteristics of the study groups are summarized in Table 1 showing the absence of significant differences in cardiovascular risk factors and cardiac clinical presentation. Similarly, angiographic and procedural characteristics (Table 2) were similar between the right coronary artery and $\mathrm{CF}$ group except for a significantly 
Table 2. Procedural characteristics of the study groups.

\begin{tabular}{|c|c|c|c|c|}
\hline & $\begin{array}{c}\text { All } \\
(n=190)\end{array}$ & $\begin{array}{l}\text { CA group } \\
(\mathrm{n}=91)\end{array}$ & $\begin{array}{l}\text { CF group } \\
(n=99)\end{array}$ & $\begin{array}{c}P \\
\text { (1 vs. 2) }\end{array}$ \\
\hline Radial approach & $145(76.3 \%)$ & $69(75.8 \%)$ & $76(76.7 \%)$ & 0.5 \\
\hline Contrast dose $[\mathrm{mL}]$ & $338.4 \pm 126$ & $341.7 \pm 125$ & $335 \pm 127$ & 0.7 \\
\hline \multicolumn{5}{|l|}{ No of disease vessels: } \\
\hline 1 vessel & $69(36.3 \%)$ & $33(36.2 \%)$ & $36(36.3 \%)$ & 0.5 \\
\hline 2 vessels & $60(31.6 \%)$ & $28(30.7 \%)$ & $32(32.3 \%)$ & 0.5 \\
\hline 3 vessels & $53(27.9 \%)$ & $24(26.3 \%)$ & $29(29.2 \%)$ & 0.4 \\
\hline \multicolumn{5}{|l|}{ No. of treated vessel: } \\
\hline 1 vessel & $111(58.4 \%)$ & $49(53.8 \%)$ & $62(62.3 \%)$ & 0.4 \\
\hline 2 vessels & $59(31 \%)$ & $30(32.9 \%)$ & $29(29.3 \%)$ & 0.5 \\
\hline 3 vessels & $4(2 \%)$ & $2(2.2 \%)$ & $2(2.0 \%)$ & 0.4 \\
\hline Complete revascularization & $141(74 \%)$ & $69(75 \%)$ & $72(73 \%)$ & 0.3 \\
\hline Assisted PCI (IABP or Impella) & $16(8.4 \%)$ & $7(7.6 \%)$ & $9(9.1 \%)$ & 0.3 \\
\hline Intravascular imaging (IVUS or OCT) & $49(26 \%)$ & $27(29.7 \%)$ & $22(22.2 \%)$ & 0.13 \\
\hline Stent length $[\mathrm{mm}]$ & $27.8 \pm 13$ & $28.6 \pm 13$ & $27.1 \pm 14$ & 0.5 \\
\hline Stent diameter $[\mathrm{mm}]$ & $3.6 \pm 0.4$ & $3.6 \pm 0.4$ & $3.6 \pm 0.5$ & 0.7 \\
\hline Multiple stents & $38(20 \%)$ & $17(19 \%)$ & $21(21 \%)$ & 0.5 \\
\hline \multicolumn{5}{|l|}{ Bifurcation strategy } \\
\hline Side branch stenting & $19(10 \%)$ & $15(16.5 \%)$ & $4(4.0 \%)$ & 0.003 \\
\hline TAP stenting & $14(7 \%)$ & $10(11 \%)$ & $4(4.0 \%)$ & 0.055 \\
\hline Other side branch stenting technique & $5(2.6 \%)$ & $5(5.5 \%)$ & $0(0 \%)$ & 0.023 \\
\hline Final kissing balloon & $123(64.7 \%)$ & $59(64.8 \%)$ & $64(64.4 \%)$ & 0.5 \\
\hline
\end{tabular}

CA — coronary angiography; CF — clinical follow-up; IABP — intra-aortic balloon pump; IVUS — intravascular ultrasound; OCT — optical coherence tomography; $\mathrm{PCl}$ - percutaneous coronary intervention; TAP — T-stenting and small protusion

Table 3. Clinical events during follow-up in the study group.

\begin{tabular}{|c|c|c|c|c|}
\hline & $\begin{array}{c}\text { All } \\
(n=190)\end{array}$ & $\begin{array}{l}\text { CA group } \\
(\mathrm{n}=91)\end{array}$ & $\begin{array}{l}\text { CF group } \\
(n=99)\end{array}$ & $\begin{array}{c}\text { P } \\
\text { (1 vs. 2) }\end{array}$ \\
\hline \multicolumn{5}{|l|}{ Primary endpoint } \\
\hline MACE (CD + MI + urgent TVR) & $20(10.5 \%)$ & $4(4.3 \%)$ & $16(16.2 \%)$ & 0.009 \\
\hline \multicolumn{5}{|l|}{ Secondary endpoints } \\
\hline Any TVR & $19(10 \%)$ & $14(15.4 \%)$ & $5(5 \%)$ & 0.014 \\
\hline CD & $7(3.7 \%)$ & $0(0 \%)$ & $7(7 \%)$ & 0.01 \\
\hline MI & $7(3.7 \%)$ & $2(2.2 \%)$ & $5(5 \%)$ & 0.3 \\
\hline Urgent TVR & $6(3.1 \%)$ & $2(2.2 \%)$ & $4(4 \%)$ & 0.3 \\
\hline $\mathrm{CD}+\mathrm{Ml}$ & $14(7.4 \%)$ & $2(2.2 \%)$ & $12(12.1 \%)$ & 0.009 \\
\hline
\end{tabular}

CA — coronary angiography; CF — clinical follow-up; CD — cardiac death; MACE — major adverse cardiac events; MI — myocardial infarction; TVR - target vessel revascularization

higher side-branch stenting $(\mathrm{p}=0.003)$ in the CA group. After a mean of $35 \pm 21$ months, a total of $20(10.5 \%)$ patients experienced MACE (Table 3$)$. MACE rates were significantly more frequent in the CF group than CA group (16.2\% vs. $4.3 \%, \mathrm{p}=$
0.009), mainly due to a significantly higher cardiac death rate $(\mathrm{p}=0.01)$. The rates of urgent TVR and MI were similar in the two groups. Any TVR rate was significantly higher in the CA group than in the $\mathrm{CF}$ group $(15.4 \%$ vs. $5 \%$ of $\mathrm{CF}, \mathrm{p}=0.014)$. 


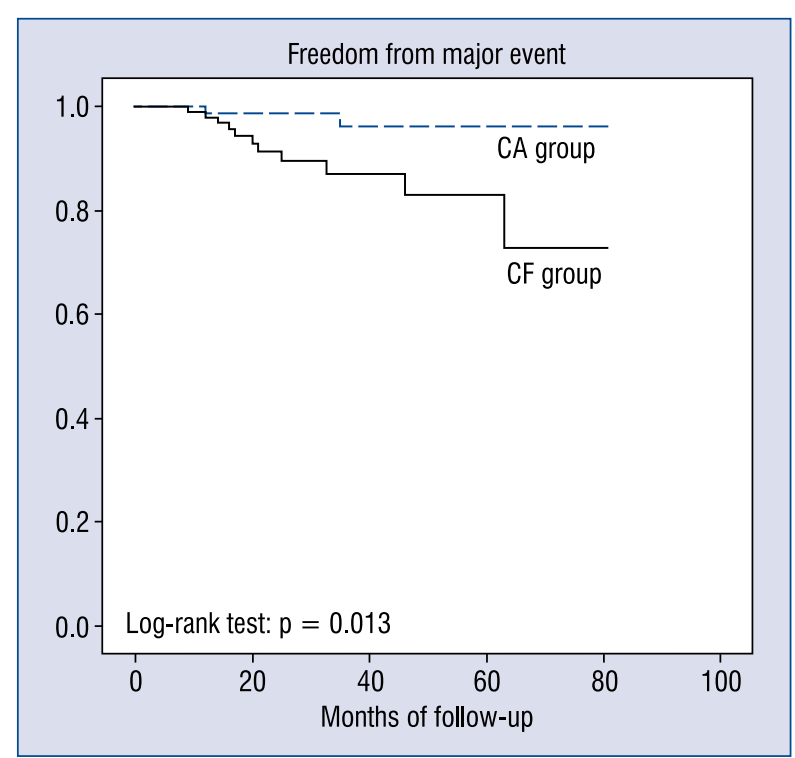

Figure 2. Kaplan-Meier major adverse cardiac eventsfree survival curves in patients with unprotected left main percutaneous coronary intervention undergoing coronary angiography (CA) or clinical follow-up (CF).

The Kaplan-Meier MACE-free survivals reported in Figure 2 shows a statistically better outcome for the CA group than $\mathrm{CF}$ group $(\mathrm{p}=0.013)$.

At univariate analysis, significant predictors of MACE were age $(\mathrm{p}=0.003)$, severe ventricular dysfunction $(\mathrm{p}=0.015)$, follow-up modality $(\mathrm{CF}$ or CA) $(\mathrm{p}<0.0001)$. At multivariable analysis, the follow-up modality (CF vs. CA) was the only independent predictor of MACE, CA being associated with a reduced risk (HR $0.13,95 \% \mathrm{CI} 0.1-0.7$, $\mathrm{p}=0.028)$.

\section{Discussion}

Previous randomized and non-randomized trials consistently reported that routine coronary angiography at follow-up increased repeat coronary revascularization without reduction in MACE, although the rate of MI was lower in the routine coronary angiography group of the sub-studies of Balloon Angioplasty and Anticoagulation Study and the TAXUS-IV trial [7-9, 16-18]. Recently the Randomized Evaluation of Routine Follow up Coronary Angiography after Percutaneous Coronary Interventional Trial (REACT) has confirmed that routine $\mathrm{CA}$ after $\mathrm{PCI}$ was not associated to clinical benefits and early coronary revascularization rates were increased within routine CA strategy [19]. However, the trial was underpowered to detect modest benefits of a routine CA after PCI and in the subgroup analyses the routine CA strategy is associated to a trend with a lower incidence of MACE in patients undergoing ULM PCI. Therefore, the impact of routine CA strategy in high risk patients, such as patients had undergone ULM PCI, in real world practice has not been fully evaluated.

The results of the present study show that routine $\mathrm{CA}$, despite being not recommended by contemporary guidelines, may be appropriate in patients undergoing successful complex PCI. In particular, patients who underwent PCI on ULM. PCI may have a major clinical benefit since an early recognition and treatment of restenosis may help reduce mortality at follow up. Several studies have demonstrated the safety and feasibility of complex PCI such as ULM PCI and many centers currently perform these procedures which are associated with considerable risk of restenosis and adverse clinical outcomes. Yet the most appropriate strategy to follow these patients after successful revascularization remains debated. Indeed, routine control angiography is often recommended between 6 and 12 months after PCI, but evidence in support of this strategy is lacking. Previous studies have reported that routine control angiography after PCI leads to higher rates of repeat interventions, without clear advantages when compared with a conservative management in which repeat angiography is reserved to patients presenting recurrent symptoms or objective sign of myocardial ischemia $[7,8,15,16]$ including patients receiving ULM PCI [20].

In the present study, the clinical impact of routine control angiography was evaluated in patients undergoing complex PCI, such as revascularization for ULM stenosis. The main finding of this study is that even if routine control angiography is associated (as expected) with a higher rate of repeat TVR, it appears to improve late outcome since the composite of cardiac death, nonfatal MI and urgent TVR was significantly reduced. Such findings may suggest that "elective" repeat revascularization procedures may have a beneficial impact on clinical outcomes in high risk patients [21,22]. In keeping with this notion, in a recent study, the evidence of asymptomatic restenosis was predictive of 4-year mortality [13]. In the same study, which was not focused on complex PCI patients, the received management (conservative or repeat revascularization) did not influence outcome [13].

Of note, the results of the present study are in contrast with that of another study on most appropriate follow up strategy in undergoing ULM PCI. Indeed, Biondi-Zoccai et al. [20] reported no 
benefit with CA vs. CF. This study has the same limitations as the present study as they were both retrospective, observational, single center register. Importantly, Biondi-Zoccai et al. [20] reported a much higher rate of angiographically-driven TVR (thus reflecting a different attitude in the management of mild restenosis) and including any TVR (not just urgent TVR) as a component of primary end-point.

Recently a multicenter registry, included consecutive patients with a critical lesion of an ULM treated with second generation DES, has demonstrated that planned angiographic control was associated with more TVR but with lower rates of cardiovascular death [23]. Although the study has a retrospective design, the number of patients enrolled has allowed propensity score balancing to correct the heterogeneity of the study groups. In the present study a similar incidence of TVR was found and a similar benefit on prognosis for patients with planned angiographic control but presently herein, have not completely removed the risk of selection bias tending to favor the performance of routine angiography in healthier patients, despite the multivariate analysis.

\section{Limitations of the study}

The major limitation of this study is the retrospective, observational and single center design as the choice of follow-up strategy was left to the referring physician and/or patient. Therefore, differences can be expected in baseline and procedural characteristics of the groups and multivariate analysis may not have completely eliminated the risk of selection bias tending to favor the performance of routine angiography in healthier patients. Furthermore, the relatively small number of patients precludes the possibility of propensity score balancing to correct heterogeneity of the study groups. The strategy of clinical follow-up is related to the referring physician discretion. Therefore, selected strategy of clinical follow-up and, specifically, the use of non-invasive tests are unknown for both study groups. In conclusion, the results of this study call for future evaluations of the clinical impact of systematic angiographic follow-up in patients who have successfully undergone ULM PCI.

\section{Conclusions}

The present study evaluated the clinical impact of routine control angiography in patients undergoing to PCI revascularization for ULM stenosis. The main finding is that even if routine control angiography is associated (as expected) with a higher rate of repeat TVR, it appears to improve late outcome since the composite of cardiac death, nonfatal MI and urgent TVR was significantly reduced, suggesting that "elective" repeat revascularization procedures may have a beneficial impact on clinical outcomes in high risk patients. The present findings are hypothesis generating and need to be confirmed by adequately powered, randomized and controlled trials.

\section{Conflict of interest: None declared}

\section{References}

1. Serruys PW, de Jaegere P, Kiemeneij F, et al. A comparison of balloon-expandable-stent implantation with balloon angioplasty in patients with coronary artery disease. Benestent Study Group. N Engl J Med. 1994; 331(8): 489-495, doi: 10.1056/ NEJM199408253310801, indexed in Pubmed: 8041413.

2. Fischman DL, Leon MB, Baim DS, et al. A randomized comparison of coronary-stent placement and balloon angioplasty in the treatment of coronary artery disease. Stent Restenosis Study Investigators. N Engl J Med. 1994; 331(8): 496-501, doi: 10.1056/ NEJM199408253310802, indexed in Pubmed: 8041414.

3. de Bono D. Complications of diagnostic cardiac catheterisation: results from 34,041 patients in the United Kingdom confidential enquiry into cardiac catheter complications. Br Heart J. 1993; 70(3): 297-300, indexed in Pubmed: 8398509.

4. Johnson LW, Krone R. Cardiac catheterization 1991: a report of the Registry of the Society for Cardiac Angiography and Interventions (SCA\&I). Cathet Cardiovasc Diagn. 1993; 28(3): 219-220, indexed in Pubmed: 8439997.

5. Devlin G, Lazzam L, Schwartz L. Mortality related to diagnostic cardiac catheterization. Int J Cardiac Imaging. 1997; 13(5): 379-384.

6. Deshpande NV, Serruys PW. Asymptomatic restenosis: should we (re)intervene? An unresolved dilemma. Am Heart J. 1998; 136(4 Pt 1): 576-577, indexed in Pubmed: 9778059.

7. Uchida T, Popma J, Stone GW, et al. The clinical impact of routine angiographic follow-up in randomized trials of drug-eluting stents: a critical assessment of "oculostenotic" reintervention in patients with intermediate lesions. JACC Cardiovasc Interv. 2010; 3(4): 403-411, doi: 10.1016/j.jcin.2010.01.010, indexed in Pubmed: 20398868.

8. Stone GW, Parise H, Witzenbichler B, et al. Selection criteria for drug-eluting versus bare-metal stents and the impact of routine angiographic follow-up: 2-year insights from the HORIZONSAMI (Harmonizing Outcomes With Revascularization and Stents in Acute Myocardial Infarction) trial. J Am Coll Cardiol. 2010; 56(19): 1597-1604, doi: 10.1016/j.jacc.2010.08.608, indexed in Pubmed: 20888162.

9. Berg Jt, Kelder J, Suttorp M, et al. Influence of planned sixmonth follow-up angiography on late outcome after percutaneous coronary intervention. J Am Coll Cardiol. 2001; 38(4): 1061-1069, doi: 10.1016/s0735-1097(01)01476-0.

10. Patel MR, Bailey SR, Bonow RO, et al. ACCF/SCAI/AATS/AHA/ ASE/ASNC/HFSA/HRS/SCCM/SCCT/SCMR/STS 2012 appro- 
priate use criteria for diagnostic catheterization: a report of the American College of Cardiology Foundation Appropriate Use Criteria Task Force, Society for Cardiovascular Angiography and Interventions, American Association for Thoracic Surgery, American Heart Association, American Society of Echocardiography, American Society of Nuclear Cardiology, Heart Failure Society of America, Heart Rhythm Society, Society of Critical Care Medicine, Society of Cardiovascular Computed Tomography, Society for Cardiovascular Magnetic Resonance, and Society of Thoracic Surgeons. J Am Coll Cardiol. 2012; 59(22): 1995-2027, doi: 10.1016/j.jacc.2012.03.003, indexed in Pubmed: 22578925.

11. Weintraub W, Ghazzal Z, Douglas J, et al. Usefulness of the Substitution of Nonangiographic End Points (Death, Acute Myocardial Infarction, Coronary Bypass and/or Repeat Angioplasty) for Follow-Up Coronary Angiography in Evaluating the Success of Coronary Angioplasty in Patients With Angina Pectoris. Am J Cardiol. 1998; 81(4): 382-386, doi: 10.1016/s0002-9149(97)00933-8.

12. Rupprecht HJ, Espinola-Klein C, Erbel R, et al. Impact of routine angiographic follow-up after angioplasty. Am Heart J. 1998; 136(4 Pt 1): 613-619, indexed in Pubmed: 9778063.

13. Schühlen H, Kastrati A, Mehilli J, et al. Restenosis detected by routine angiographic follow-up and late mortality after coronary stent placement. Am Heart J. 2004; 147(2): 317-322, doi: 10.1016/j.ahj.2003.10.002, indexed in Pubmed: 14760331.

14. Thygesen K, Alpert JS, Jaffe AS, et al. Joint ESC/ACCF/AHA/ /WHF Task Force for Universal Definition of Myocardial Infarction; Third universal definition of myocardial infarction. J Am Coll Cardiol. 2012; 60(16): 1581-1598.

15. Cassese S, Byrne RA, Schulz S, et al. Prognostic role of restenosis in 10004 patients undergoing routine control angiography after coronary stenting. Eur Heart J. 2015; 36(2): 94-99, doi: 10.1093/eurheartj/ehu383, indexed in Pubmed: 25298237.

16. Ruygrok PN, Melkert R, Morel MA, et al. Does angiography six months after coronary intervention influence management and outcome? Benestent II Investigators. J Am Coll Cardiol. 1999; 34(5): 1507-1511, indexed in Pubmed: 10551700.
17. Lansky AJ, Brar SS, Yaqub M, et al. Impact of routine angiographic follow-up after percutaneous coronary intervention with drug-eluting stents in the SPIRIT III randomized trial at three years. Am J Cardiol. 2012; 110(1): 21-29, doi: 10.1016/j.amjcard.2012.02.040, indexed in Pubmed: 22464212.

18. Pinto DS, Stone GW, Ellis SG, et al. TAXUS-IV Investigators. Impact of routine angiographic follow-up on the clinical benefits of paclitaxel-eluting stents: results from the TAXUS-IV trial. J Am Coll Cardiol. 2006; 48(1): 32-36, doi: 10.1016/j.jacc.2006.02.060, indexed in Pubmed: 16814645.

19. Shiomi H, Morimoto T, Kitaguchi S, et al. The ReACT Trial: Randomized Evaluation of Routine Follow-up Coronary Angiography After Percutaneous Coronary Intervention Trial. JACC Cardiovasc Interv. 2017; 10(2): 109-117, doi: 10.1016/j. jcin.2016.10.018, indexed in Pubmed: 28040445.

20. Biondi-Zoccai GGL, Giraudi E, Moretti C, et al. Impact of routine angiographic follow-up after percutaneous coronary drug-eluting stenting for unprotected left main disease: the Turin Registry. Clin Res Cardiol. 2010; 99(4): 235-242, doi: 10.1007/s00392-0090112-3, indexed in Pubmed: 20047051.

21. Alfonso F, Byrne RA, Rivero F, et al. Current treatment of in-stent restenosis. J Am Coll Cardiol. 2014; 63(24): 2659-2673, doi: 10.1016/j.jacc.2014.02.545, indexed in Pubmed: 24632282.

22. Park SJ, Kang SJ, Virmani R, et al. In-stent neoatherosclerosis: a final common pathway of late stent failure. J Am Coll Cardiol. 2012; 59(23): 2051-2057, doi: 10.1016/j.jacc.2011.10.909, indexed in Pubmed: 22651862.

23. D'Ascenzo F, Iannaccone M, Pavani M, et al. Planned angiographic control versus clinical follow-up for patients with unprotected left main stem stenosis treated with second generation drug-eluting stents: A propensity score with matching analysis from the FAILS (failure in left main with second generation stentsCardiogroup III Study). Catheter Cardiovasc Interv. 2017 [Epub ahead of print], doi: 10.1002/ccd.27408, indexed in Pubmed: 29130573. 